\title{
BMJ Open So near yet so far: why won't the UK prescribe medical cannabis?
}

\author{
David Nutt, ${ }^{1}$ Steve Bazire, ${ }^{2}$ Lawrence D Phillips, ${ }^{3}$ Anne Katrin Schlag (D) 4
}

To cite: Nutt D, Bazire $S$, Phillips LD, et al. So near yet so far: why won't the UK prescribe medical cannabis? BMJ Open 2020;10:e038687. doi:10.1136/ bmjopen-2020-038687

- Prepublication history for this paper is available online. To view these files, please visit the journal online (http://dx.doi org/10.1136/bmjopen-2020038687).

Received 19 March 2020 Revised 25 June 2020 Accepted 08 July 2020
Check for updates

(C) Author(s) (or their employer(s)) 2020. Re-use permitted under CC BY-NC. No commercial re-use. See rights and permissions. Published by BMJ.

${ }^{1}$ Faculty of Medicine, Imperial College London, London, UK ${ }^{2} \mathrm{NHS}$, Redditch, UK

${ }^{3}$ Department of Management, London School of Economics and Political Sciences, London, UK

${ }^{4}$ Drug Science, London, UK

Correspondence to

Professor David Nutt;

d.nutt@imperial.ac.uk

\begin{abstract}
Although cannabis-based products for medicinal use are now legal in the UK, it is still challenging for patients to gain access, and only very few National Health Service prescriptions have been written to date. This paper attempts to make sense of why the UK lags behind so many other countries which also have legalised medical cannabis. From consulting with parents and patients, prescribers, pharmacists and decision-makers it seems that there are a series of distinct barriers to prescribing that need to be overcome in order to improve patient access to medical cannabis in the UK. These include concerns about the perceived lack of scientific evidence. To alleviate these concerns, we highlight the importance of patient-centred approaches including patient-reported outcomes, pharmacoepidemiology and $n=1$ trials, which can contribute to the development of the evidence base for medical cannabis. We hope that this paper will help policymakers and prescribers understand the challenges to prescribing and so help them develop approaches to overcome the current situation which is detrimental to patients.
\end{abstract}

\section{INTRODUCTION}

In November 2018 when the UK made cannabis-based products for medicinal use (CBPMs) legal most people assumed these would immediately be made available to patients, but they were wrong. In the year since almost no National Health Service (NHS) prescriptions have been issued ${ }^{1}$ and less than a hundred have been made available from private providers at a cost of at least $£ 1000$ a month. $^{2}$ For these reasons, some parents of children with severe epilepsy continue to go overseas to get their children access to the only treatment which has proven to be effective for their condition, that is, a cannabinoid medication. Moreover, the vast majority of the estimated 1.4 million medical cannabis users ${ }^{3}$ source from the black market with its problems of illegality, unknown quality, content and provenance. Given the substantial evidence of utility of CBPMs in many disorders as identified in the US National Academy of Sciences review in $2017^{4}$ this failure of delivery in the UK seems odd and, to many, inexcusable.
Strengths and limitations of this study

- There are a series of distinct barriers to prescribing medical cannabis that need to be overcome in order to improve patient access in the UK.

- Concerns about the perceived lack of randomised controlled trial evidence are misplaced as many patient-centred approaches including patientreported outcomes, pharmacoepidemiology and $\mathrm{n}=1$ trials can be applied.

- Thousands of UK patients self-medicating with illicit cannabis-based products for medicinal use and the international database evidence suggest this new class of drugs offers a significant advance in treatment for many in whom current medicines are either ineffective or poorly tolerated.

- We hope that this paper will help policymakers and prescribers understand the challenges to prescribing and so help them develop approaches to overcome the current unsatisfactory situation.

CONCERNS ABOUT PERCEIVED LACK OF EVIDENCE Statements such as 'insufficient evidence of efficacy' or 'it is too dangerous' are common and used even in the face of strong personal evidence from patients that CBPMs work and, in many cases, can be life-changing and well tolerated. Many doctors fail to include the evidence of the patient's lived experience and cite the lack of placebo-controlled trials in every possible indication for their hesitation to prescribe. While tens of thousands of individual patient reports of the therapeutic value of CBPMs as in the Canadian and Minnesota databases ${ }^{5}$ do not equate to the so-called gold-standard double-blind randomised controlled trial (RCT) level of proof, they are highly suggestive of a pattern of evidence which should be taken seriously rather than summarily dismissed. These large-scale databases could be further interrogated and systematically analysed to collate patient-reported outcomes (PROs) and other existing evidence for peer-reviewed publications. In the UK, Drug Science recently launched Project TWENTY21, the largest national medical cannabis registry in Europe, with the aim to create a structured body of 
evidence for the effectiveness and tolerability of medical cannabis for a broad range of conditions (https://drugscience.org.uk/project-twenty21/). Moreover, Drug Science is also currently working on audits using existing data of patients with epilepsy prescribed medical cannabis, showing, for example, a clear reduction of seizures after medical cannabis use.

The major criticism of the lack of placebo-controlled trials is misplaced. Prescribers often mistakenly state that without these they cannot prescribe. However, there are over 50 medicines or indications that have been licensed by Food and Drug Administration and/or European Medicines Agency between 1999 and 2014 without RCT data. $^{7}$

Moreover, the ex-head of National Institute for Health and Care Excellence (NICE) and the Medicines and Healthcare products Regulatory Agency, Sir Michael Rawlins, challenged this RCT preconception in the 2008 Harvean Oration, highlighting that:

Randomised controlled trials (RCTs), long regarded at the 'gold standard' of evidence, have been put on an undeserved pedestal. Their appearance at the top of 'hierarchies' of evidence is inappropriate; and hierarchies, themselves, are illusory tools for assessing evidence. They should be replaced by a diversity of approaches that involve analysing the totality of the evidence-base. $^{8}$

Placebo-controlled double-blind trials are clearly a very important element of medicine where their primary role is to provide evidence for companies to get a marketing authorisation. Such trials are done in tightly selected patient groups that are not representative of the average patient who often has many different medical comorbidities. Therefore, even when such trials are positive, they are only suggestive of efficacy in the wider patient groups and other approaches such as effectiveness trials or clinical audits are required to properly estimate real-world value to individual patients.

Of these new approaches, PROs are probably the most significant development. These have received immense investment from the US National Institutes of Health (NIH) and many new scales have been developed for this purpose. PRO measures are now required as elements of outcome measures for clinical trials funded by the NIH in the USA (https://commonfund.nih.gov/promis/index. PROs put more emphasis on the patient's life and wellbeing and have been shown to be more sensitive to the effects of medical cannabis than traditional symptombased measures. For example, a large recent naturalistic German study on pain syndromes using PROs found adding a CBPM very significantly improved outcomes in patients with neuropathic pain. ${ }^{9}$ Other recent papers showing real-world benefits from CBPMs using patient reports have been reported in Parkinson's disease ${ }^{10}$ and autism. ${ }^{11}$ NICE has developed a cadre of expert patients to advise them of the patients' perspective (https://www.sciesocialcareonline.org.uk/the-expert-patients-rogramme/
r/a1CG0000000GNbcMAG) although it is not apparent if this includes a patient with experience of medical cannabis. Progress in this direction has led to the setting up of a special centre in Cambridge for patient-led research in the clinical trials unit: https://www.cuh.nhs. uk/clinical-trials/cambridge-clinical-trials-unit-cctu/ patient-led-research-hub.

Pharmacoepidemiology and, specifically, observational research is another recent patient-centred approach to study the effectiveness of real-world medication. ${ }^{12}$ Advantages include the availability of large patient samples, coverage of under-researched subpopulations in their naturalistic conditions and lower costs than RCTs. ${ }^{13}$ The limitation of the non-randomised nature of treatment selection can be addressed by including comparison groups, or through the triangulation of multiple analytical approaches to improve confidence in inferred causal relationships.

With many clinicians demanding better and faster evidence to inform their decisions around prescribing CBPMs, these newer approaches offer potential solutions to the lack of RCTs. Indeed, in line with rapid developments in data resources and analytical techniques, many guidelines are now beginning to include evidence from robust observational pharmacoepidemiological studies alongside RCTs. ${ }^{13}$

But even more important are the $n=1$ trials, for these are the core of medical practice since every time a medicine is prescribed an $n=1$ experiment is being conducted. In some patients the experiment works and in others it fails, the patient either does not respond or the adverse effects outweigh the therapeutic benefit. One might therefore expect that doctors would welcome patients who have conducted successful self-treatment with cannabis since it is almost certain that prescribing medical cannabis to these will work, providing a therapeutic win for both patient and prescriber.

The resurrection of CBPMs following its banning by the United Nations Conventions is directly attributable to $n=1$ trials conducted in children with intractable epilepsy. The first patient was Charlotte Web in the USA who inspired UK parents of children with similar epilepsies notably Alfie Dingley and Billy Caldwell. These children were facing death and/or brain damage from multiple seizures resistant to licensed treatments and CBPMs restored them to close to normality and also allowed them to come of other medicines. In the case of Billy, the proof of therapeutic efficacy was dangerously established by the confiscation of his medical cannabis by UK customs which led to a life-threating episode of status epilepticus requiring admission to intensive care. The public outcry over such callous treatment by the UK government was the immediate cause of the rescheduling of medical cannabis in November 2018.

In scientific terms Billy was the subject of an A-B-A design, one of the most powerful methodologies for examining a medical intervention. The UK government accepted that in these cases CBPMs worked. So why would 
any prescriber resist similar claims in their patients, particularly if they had seen their own previously prescribed treatments fail? In such cases to deny a patient a CBPM simply because they are using an 'illegally' sourced preparation is illogical and could be construed as being unethical. Germany took this view when deciding to make medical cannabis available. The General Medical Council (GMC) guidance on good medical practice makes it clear that all registered doctors must take into account and respect patients' views and experience.

Scientific support for ABA trials is well established in educational, behavioural and psychological assessment but less so in medical research. ${ }^{1415} \mathrm{An} \mathrm{ABA(B)} \mathrm{trial} \mathrm{design}$ is well suited for determining whether medical cannabis is efficacious. Bayesian analysis can also combine separate $\mathrm{ABA}(\mathrm{B})$ results from different populations of patients, such as cannabis and non-cannabis users, stratified as suggested by experts whose experience has identified possible confounding variables. ${ }^{16}$ This approach is known as multilevel regression and poststratification. ${ }^{17}$

\section{WHAT ARE THE REASONS FOR THIS RESISTANCE?}

One source of this resistance is that because CBPMs are patient driven, to welcome them would be an admission that the patients are more knowledgeable than the doctor. Despite over a decade of demands by the Department of Health and Social Care (DHSC) for patients to have a say in medical practice in the UK, there has been little progress. In this debate it is usually forgotten that cannabis was a licensed medicine in the UK before 1971. So why does the government not just reissue the license that applied then? Phenergan and chloral hydrate have continued to be available in the UK since that time despite no doubleblind clinical trial data and chloral is sometimes used as an antiepilepsy treatment in the children with epilepsy who are denied CBPMs!

Another factor is the 'not invented here' syndrome. UK prescribers often say they only trust data collected here; an attitude justified by our high-quality health technology assessment processes especially NICE. However, to ignore data from other countries in a field as complicated as medical cannabis likely distorts the truth. Medical cannabis has been available for over a decade in many states in the USA and there are nearly 20000 patients on the Minnesota database, providing detailed data on various conditions and PROs since 2015. These data should be interrogated and formally published as a way to accelerate clinically relevant information to potential prescribers as the Health Secretary Matt Hancock stated in July 2019. ${ }^{18}$

This statement calls into question the current DHSC rule that medical cannabis must be considered a 'Special'. The challenges of Specials to prescribers are not trivial and include:

1. Organisational bureaucracy and the subsequent delay of prescribing, approval and supply.
2. Transferring a patient between one sector and another, especially where, for example, primary care will not continue prescribing of a superficially expensive special or unlicensed product.

3. Local secondary and primary care services having different rules and guidance, particularly about prescribing unlicensed medicines.

4. Responsibility for prescribing - a licensed product's manufacturer is accountable for any untold harm if the product is used within the license, but with an unlicensed product or Special the prescriber assumes responsibility for any harm that occurs, unless it can be directly attributed to a defect in the actual product.

These complexities do give some support to doctors' perception of prescribing as too difficult. Moreover, the DHSC has made cannabis a special 'special' as prescribing requires a special pink pad that has to be ordered. Why such constraints are required is unclear given the established safety of cannabis medicines, but they are problematic for the prescriber and likely deter use.

Most UK doctors have no experience of medical cannabis and comments like 'I don't know what to prescribe' are often heard. Though understandable they reflect poorly on a profession which generally welcomes engaging with new therapeutics; until medical cannabis came along prescribers were rarely fearful of new therapeutics. Moreover, new is not really a credible term given the decade of CBPMs in USA, Canada and the Netherlands, and its subsequent publications on the practical considerations in medical cannabis administration and dosing. ${ }^{19}$ The 1998 House of Lords report on medical cannabis provided clear evidence on efficacy and value of medical cannabis. ${ }^{20}$ Both delta-9-tetrahydrocannabinol (THC) (eg, as nabilone) and a mixture of delta-9-THC and cannabidiol (as Sativex, made from whole plant extracts) have been licensed medicines in the UK for over a decade. The decision to move cannabis to Schedule 2 was made on the basis that there were adequate data that it was a medicine. ${ }^{21}$ While there is little in the way of teaching on medical cannabis in the undergrad or postgrad medical curricula, the past couple of years have seen an increasing amount of medical cannabis educational programmes of varying standards. Especially for clinicians it is essential to be able to find non-biased educational programmes, highlighting the need for accredited training to be made available. Drug Science is currently offering free online teaching courses on medical cannabis and is also working on the development of accredited courses together with the Society for the Study of Addiction.

Perhaps one reason for resistance to CBPMs is that for nearly 50 years the medical profession focused on the risks of cannabis with extreme claims of harms, including male sterility, lung cancer and schizophrenia. Though these have now been largely debunked and were generally the result of recreational rather than prescribed medical use, many practitioners may not know this. Even if they do, there can be significant concern in prescribing 
a drug that has been vilified for decades as toxic. Here education is the solution.

Furthermore, patients self-medicating are often using the same illicitly sourced products as recreational users, making differentiation between uses challenging for clinicians. For both patient and doctor, access to fully regulated products could ensure a known dose and a quality and content that can actually be monitored.

\section{THE PHARMACY PERSPECTIVE}

Pharmacists (especially at Clinical Commissioning Group level) and medical prescribing advisors also play a significant role, often through area prescribing committees (APCs). Pharmacy advisors tend to think of themselves as guardians of the public purse in relation to medicines prescribing. Their default position is usually to resist the cost implications of new medicines by blocking approval to local prescribing lists. Here the resistance is often derived from a misplaced focus of prescription costs with the cost benefits of saving in other medicines and interventions being ignored; for example, medical cannabis can reduce the use of strong opioids, ${ }^{22}{ }^{23}$ and lower prescription costs. ${ }^{24}$

We suggest that APCs should give CBPMs a fair chance by:

- Ensure better training locally.

- Agreeing with the relevant consultants, for example, pain or neurology clinics, a specified number of patients each year.

- Factor in the costs of the alternatives, for example, opioid overuse (due to lack of efficacy for many pains), benzodiazepines and pregabalin/gabapentin overmedication or self-medication.

- Take genuine notice of testimonies from patients, who will not be diverting CBPMs because they need it.

- Remember that generic substitution of CBPMs is challenging as all products have different ratios of THC and Cannabidiol (CBD) and may give different actions.

- Remember that there are many CBPMs with low THC or absent of THC. Also, the common routes of ingestion (ie, oral oil/capsule) make it unlikely for patients to have immediate intoxication effects.

- In order to clarify cost implications of prescribing CBPMs, it is essential to conduct a full health economic analysis. Quality cost savings analyses are lacking at present and will be important for governments to enable active changes.

\section{CONCLUSIONS}

The many thousands of UK patients self-medicating with non-regulated CBPMs and the international database evidence suggest these new medical products offer a significant advance in treatment for many in whom current medicines are either ineffective or poorly tolerated. They also offer the potential of significant cost savings to the NHS in terms of reduced hospital stays and less prescribing of other medicines particularly opioids for chronic pain. The failure of the medical and pharmacy professions to embrace CBPMs despite their being made 'legal' over 18 months ago is a great worry to patients and will already likely have led to preventable deaths from conditions such as epilepsy. We hope that this paper will help policymakers and prescribers understand the challenges to prescribing and so help them develop approaches to overcome the current highly unsatisfactory situation.

Correction notice This article has been corrected since it was published. The competing interests statement has been updated.

Contributors DN is the guarantor and developed the initial manuscript. LDP and AKS developed the section on concerns about perceived lack of evidence, and the importance of $n=1$ trials. SB wrote the pharmacy perspective, and the suggested guidance for area prescribing committees. All authors reviewed the manuscript and agreed on the final submission.

Funding The authors have not declared a specific grant for this research from any funding agency in the public, commercial or not-for-profit sectors.

Competing interests DN is Chair of the charity Drug Science and AKS is Head of Research of Drug Science. Drug Science receives an unrestricted educational grant from a consortium of medical cannabis companies to further its mission, that is the pursuit of an unbiased and scientific assessment of drugs regardless of their regulatory class. All Drug Science committee members, including the Chair, are unpaid by Drug Science for their effort and commitment to this organisation. AKS is scientific advisor to the Primary Care Cannabis Network, and an executive member of the Cannabis Industry Council, both unpaid roles. None of the authors would benefit from the wider prescription of medical cannabis in any form.

Patient consent for publication Not required.

Provenance and peer review Not commissioned; externally peer reviewed.

Open access This is an open access article distributed in accordance with the Creative Commons Attribution Non Commercial (CC BY-NC 4.0) license, which permits others to distribute, remix, adapt, build upon this work non-commercially, and license their derivative works on different terms, provided the original work is properly cited, appropriate credit is given, any changes made indicated, and the use is non-commercial. See: http://creativecommons.org/licenses/by-nc/4.0/.

\section{ORCID iD}

Anne Katrin Schlag http://orcid.org/0000-0003-2074-1917

\section{REFERENCES}

1 Sumnall $\mathrm{H}$. Medicinal cannabis: legalised yet impossible to access. The independent. Available: https://www.independent.co.uk/lifestyle/health-and-families/health-news/medicinal-cannabis-legalisedaccess-marijuana-nhs-a8903051.html [Accessed 13 May 2019].

2 Wickware C. Nhs England cannabis access review to speak with families paying £40k for private prescriptions. The pharmaceutical. Available: https://www.pharmaceutical-journal.com/news-andanalysis/news/nhs-england-cannabis-access-review-to-speakwith-families-paying-40k-for-private-prescriptions/20206525.article [Accessed 13 May 2019].

3 Couch D. Left behind: the scale of illegal cannabis use for medicinal intent in the UK, 2020. Available: https://www.thecmcuk.org/leftbehind-the-scale-of-illegal-cannabis-use-for-medicinal-intent-intheuk [Accessed 11 Jun 2020].

4 National Academies of Sciences, Engineering, and Medicine (NASEM). The health effects of cannabis and cannabinoids: the current state of evidence and recommendations for research. Washington, DC: The National Academies Press, 2017.

5 Health Canada. Canada vigilance adverse reaction online database. Available: https://www.canada.ca/en/health-canada/services/drugshealth-products/medeffect-canada/adverse-reaction-database.html [Accessed 11 Jun 2020].

6 Minnesota Department of Health : Medical Cannabis Programme Data. Available: https://www.health.state.mn.us/people/cannabis/ data/index.html [Accessed 11 Jun 2020]. 
7 Hatswell AJ, Baio G, Berlin JA, et al. Regulatory approval of pharmaceuticals without a randomised controlled study: analysis of EMA and FDA approvals 1999-2014. BMJ Open 2016:6:e011666.

8 The Royal College of physicians: Sir Michael Rawlins attacks traditional ways of assessing evidence, opinion former article 16 October, 2008. Available: https://www.politics.co.uk/opinion-formers/ royal-college-of-physicians/article/royal-college-of-physicians-sirmichael-rawlins-attacks-trad

9 Ueberall MA, Essner U, Mueller-Schwefe GH. Effectiveness and tolerability of THC:CBD oromucosal spray as add-on measure in patients with severe chronic pain: analysis of 12-week open-labe real-world data provided by the German Pain e-Registry. J Pain Res 2019;12:1577-604.

10 Balash Y, Bar-Lev Schleider L, Korczyn AD, et al. Medical cannabis in Parkinson disease: real-life patients' experience. Clin Neuropharmacol 2017;40:268-72.

11 Bar-Lev Schleider L, Mechoulam R, Saban N, et al. Real life experience of medical cannabis treatment in autism: analysis of safety and efficacy. Sci Rep 2019;9:200.

12 Steinhubl SR, Wolff-Hughes DL, Nilsen W, et al. Digital clinical trials: creating a vision for the future. NPJ Digit Med 2019;2:126.

13 Davis KAS, Farooq S, Hayes JF, et al. Pharmacoepidemiology research: delivering evidence about drug safety and effectiveness in mental health. Lancet Psychiatry 2020;7:363-70.

14 Lillie EO, Patay B, Diamant J, et al. The n-of-1 clinical trial: the ultimate strategy for individualizing medicine? Per Med 2011;8:161-73.

15 Porcino AJ, Shamseer L, Chan A-W, et al. Spirit extension and elaboration for $n$-of- 1 trials: spent 2019 checklist. BMJ 2020;368:m122.
16 Zucker DR, Ruthazer R, Schmid CH. Individual (n-of-1) trials can be combined to give population comparative treatment effect estimates: methodologic considerations. J Clin Epidemiol 2010;63:1312-23.

17 Spiegelhalter D. The art of statistics: leaning from data. United Kingdom: Penguin Random House, 2019.

18 Uk trials not needed for medical cannabis licensing process, says Hancock. The pharmaceutical Journal. Available: https://www. pharmaceutical-journal.com//news-and-analysis/news-in-brief/ uk-trials-not-needed-for-medical-cannabis-licensing-process-sayshancock/20206808.fullarticle?firstPass=false [Accessed 15 Jul 2019].

19 MacCallum CA, Russo EB, Rosso E. Practical considerations in medical cannabis administration and dosing. Eur J Intern Med 2018;49:12-19.

20 House of Lords report. cannabis: the scientific and medical evidence, 1998. Available: https://publications.parliament.uk/pa/ld199798/ Idselect/ldsctech/151/15102.htm [Accessed 11 Jun 2020].

21 Davis DS. Cannabis scheduling review part 1- the therapeutic and medicinal benefits of cannabis based products - a review of recent evidence, 2018. Available: https://assets.publishing.service.gov.uk/ government/uploads/system/uploads/attachment data/file/722010/ CMO_Report_Cannabis_Products_Web_Accessible.pdf [Accessed 11 Jun 2020].

22 McMichael BJ, Van Horn RL, Viscusi WK. The impact of cannabis access laws on opioid prescribing. J Health Econ 2020;69:102273.

23 Boehnke KF, Litinas E, Clauw DJ. Medical cannabis use is associated with decreased opiate medication use in a retrospective cross-sectional survey of patients with chronic pain. J Pain 2016;17:739-44.

24 Bellnier T, Brown GW, Ortega TR. Preliminary evaluation of the efficacy, safety, and costs associated with the treatment of chronic pain with medical cannabis. Ment Health Clin 2018;8:110-5. 
Correction: So near yet so far: why won't the UK prescribe medical cannabis?

Nutt D, Bazire S, Phillips LD, et al. So near yet so far: why won't the UK prescribe medical cannabis? BMJ Open 2020;10:e038687. doi:10.1136/bmjopen-2020-038687

This article was previously published with an error.

The competing interests statement has been updated to:

DN is Chair of the charity Drug Science and AKS is Head of Research of Drug Science. Drug Science receives an unrestricted educational grant from a consortium of medical cannabis companies to further its mission, that is the pursuit of an unbiased and scientific assessment of drugs regardless of their regulatory class. All Drug Science committee members, including the Chair, are unpaid by Drug Science for their effort and commitment to this organisation. AKS is scientific advisor to the Primary Care Cannabis Network, and an executive member of the Cannabis Industry Council, both unpaid roles. None of the authors would benefit from the wider prescription of medical cannabis in any form.

Open access This is an open access article distributed in accordance with the Creative Commons Attribution Non Commercial (CC BY-NC 4.0) license, which permits others to distribute, remix, adapt, build upon this work non-commercially, and license their derivative works on different terms, provided the original work is properly cited, appropriate credit is given, any changes made indicated, and the use is non-commercial. See: http://creativecommons.org/licenses/by-nc/4.0/.

(c) Author(s) (or their employer(s)) 2022. Re-use permitted under CC BY-NC. No commercial re-use. See rights and permissions. Published by BMJ.

BMJ Open 2022;12:e038687corr1. doi:10.1136/bmjopen-2020-038687corr1

A) Check for updates 